\title{
Peptic ulcer in rheumatoid arthritis
}

\author{
D FARAH, ${ }^{1}$ R D STURROCK, ${ }^{2}$ AND R I RUSSELL ${ }^{1}$ \\ From the ${ }^{1}$ Department of Gastroenterology and the ${ }^{2}$ Centre for Rheumatic Diseases, Royal Infirmary \\ Glasgow
}

SUMMARY In a study of patients attending a rheumatology clinic 230 unselected patients, $18 \mathscr{W}^{2}$ with rheumatoid arthritis (RA) and 45 with other rheumatic disorders (non-RA), were examine委 by endoscopy and a detailed history of symptoms referable to the gastrointestinal tract was takene A peptic ulcer was found in $67(36 \%)$ of the patients and in $13(29 \%)$ of the non-RA groupos Gastric ulceration was more common in the group with RA (32 patients $(17 \%)$ compared witli three patients (7\%) in the non-RA group); $17 / 32$ (53\%) patients with RA and gastric ulcer were्ठ asymptomatic. In the group with RA, of those with gastric ulcer $20 / 32(63 \%)$ were smokers, compared with only $40 / 118(34 \%)$ of the non-ulcer group. There was no difference in the duration of rheumatic disease or non-steroidal anti-inflammatory drug (NSAID) treatment between the ulcer and non-ulcer groups. Treatment with $\mathrm{H}_{2}$ receptor antagonist and maintenance of NSAID. treatment resulted in healing in 26 out of $29(90 \%)$ patients with gastric ulcer and 23 out of $2 \mathscr{\%}_{0}^{\circ}$ $(85 \%)$ patients with duodenal ulcer.

Key words: non-steroidal anti-inflammatory drugs, $\mathrm{H}_{2}$ antagonists, arthritis.

There has been much recent interest in the association between peptic ulceration, non-steroidal antiinflammatory drugs (NSAIDs), and rheumatoid arthritis (RA). ${ }^{1}$ The Committee on Safety of Medicines has drawn attention to the risks of gastrointestinal haemorrhage in elderly patients receiving NSAIDs, ${ }^{23}$ and several reports have confirmed this association. ${ }^{4}$ Iron deficiency anaemia is a common feature of RA and is often caused by an asymptomatic peptic ulcer. The aetiology of peptic ulceration in RA is controversial, and it is not clear whether the apparent increase in peptic ulceration in this condition is due to the disease itself or to the drugs commonly used in treatment. We have, therefore, studied the prevalence of peptic ulceration in our patients with RA attending a rheumatology clinic, and compared them with subjects with other rheumatic diseases.

\section{Patients and methods}

A series of consecutive patients with RA attending a rheumatology outpatient clinic were asked if they

Accepted for publication 6 November 1987.

Correspondence to Dr R D Sturrock, Centre for Rheumatic Diseases, University Department of Medicine, Royal Infirmary, 10 Alexandra Parade, Glasgow G31 2ER. would agree to fibre optic endoscopy and were thep enrolled in the study after informed consent hat been given. All were receiving regular NSAIE treatment. A detailed history of gastrointestinas symptoms was taken, recording the presence of nausea, vomiting, epigastric pain, heartburn, flatuo lence, and acid eructation, together with a record of smoking habits and details of steroid and NSAII treatment. Patients studied did not have anorexia o를 weight los: and had never had haematemesis of melaena. A íamily history of peptic ulcer was sought in each case. Fifty six individuals who had endoscos pic evidence of a peptic ulcer were treated witho ranitidine $150 \mathrm{mg}$ twice a day and their NSAID waS continued. Repeat endoscopy was performed monthly intervals until the ulcer healed. A group do 45 patients who were receiving regular NSAIQ treatment and had a variety of chronic rheumatio diseases, including ankylosing spondylitis, osteoaro thritis, gout, and systemic lupus erythematosus? were also included in the study.

STATISTICAL ANALYSIS

Differences in proportions were calculated by analysis with a continuity correction (Yates's correç tion) for small numbers. Confidence intervals are quoted for the differences observed. 


\section{Results}

One hundred and eighty five patients with RA and 45 non-RA patients were studied. The two groups were matched for age by decades-mean age of patients with RA 55 years (range 19-82), non-RA patients 47.5 years (range $30-72$ ). Table 1 shows the prevalence and site of peptic ulceration in the two groups. It can be seen that there was an increased prevalence in the RA group with a large increase in gastric ulceration which was not significant at the $5 \%$ level owing to the wide confidence intervals observed-a problem arising from the relatively small sample size.

A surprising finding was the low prevalence of gastrointestinal symptoms in the RA group with a gastric ulcer, $14 / 32(44 \%)$, when compared with the non-ulcer group, $81 / 118(69 \%)$. In both the RA and non-RA groups the mean age of the patients with gastric ulcer was higher than that of patients with a duodenal ulcer (DU) and non-ulcer patients, and smoking was a major factor in predisposing to peptic ulceration in all patients (Table 2), with a suggestion that there were more smokers in the RA group as a whole. There was no correlation between peptic ulceration, disease duration, or NSAID dosage in the RA group. Steroids were taken by only four patients with RA, of whom two had an ulcer, with one non-RA patient taking regular steroids.

Table 1 Occurrence and site of peptic ulcer

\begin{tabular}{|c|c|c|c|c|}
\hline & \multicolumn{2}{|c|}{$R A \quad(n=185)$} & \multicolumn{2}{|c|}{ Non-RA $(n=45$} \\
\hline & No & $\%$ & No & $\%$ \\
\hline Gastric ulcer & 32 & $17^{*}$ & 3 & 7 \\
\hline Duodenal ulcer & 29 & 16 & 8 & 18 \\
\hline Combined & 6 & 3 & 2 & 4 \\
\hline Total & 67 & 36 & 13 & 29 \\
\hline
\end{tabular}

${ }^{*} \chi^{2}=2 \cdot 40$ (two tailed), $p=0 \cdot 117,95 \%$ confidence interval $=0 \cdot 008$ to $0 \cdot 19$.

Table 2 Age and smoking in peptic ulceration

\begin{tabular}{llll}
\hline & $\begin{array}{l}\text { Gastric } \\
\text { ulcer }\end{array}$ & $\begin{array}{l}\text { Duodenal } \\
\text { ulcer }\end{array}$ & Non-ulcer \\
\hline $\begin{array}{l}\text { Patients with } R A \\
\text { Mean age (range), years } \\
\% \text { smokers }\end{array}$ & $61(44-75)$ & $46(26-64)$ & $54(19-82)$ \\
& 63 & 65 & 34 \\
$\begin{array}{l}\text { Non-RA patients } \\
\begin{array}{l}\text { Mean age (range), years } \\
\% \text { smokers }\end{array}\end{array}$ & $67(52-70)$ & $38 \cdot 5(30-54)$ & $49(36-72)$ \\
\hline
\end{tabular}

Table 3 Peptic ulceration in RA-response to treatment

\begin{tabular}{lllll}
\hline $\begin{array}{l}\text { No of patients } \\
\text { with: }\end{array}$ & \multicolumn{4}{l}{ Endoscopy } \\
\cline { 2 - 5 } & 0 & 4 & 8 & 12 \\
\hline Gastric ulcer & 29 & $16(45)^{*}$ & $5(83)$ & $3(90)$ \\
Duodenal ulcer & 27 & $15(44)$ & $4(85)$ & $4(85)$ \\
\hline
\end{tabular}

* Percentage healed ulcers in brackets.

Fifty six patients with RA and a peptic ulcer underwent treatment with ranitidine $150 \mathrm{mg}$ twice a day and were examined by endoscopy before starting treatment and at monthly intervals until ulcer healing had been achieved. No change in NSAID treatment was made. Table 3 shows the healing rates for patients with gastric ulcer and duodenal ulcer. No comparisons could be made with healing rates in the non-RA group in view of the small number of patients with ulcers in this group.

\section{Discussion}

This survey has demonstrated a high prevalence of peptic ulceration in patients with RA who are taking NSAIDs on a regular basis. The patient group used for comparison were also receiving NSAID treatment and yet there was a greater prevalence of gastric ulceration in the RA group which could not be accounted for by factors such as age or quantity and number of NSAIDs consumed. Smoking was certainly a factor associated with peptic ulceration in RA, and this confirms the findings of a similar, albeit retrospective, survey of a rheumatology clinic. ${ }^{5}$ Gastroenterologists and rheumatologists have had the strong clinical impression that NSAID treatment, and in particular indomethacin, can cause prepyloric ulceration in RA. ${ }^{6}$ In this study prepyloric ulceration was observed more commonly in the patients with RA but was not associated with any particular NSAID. One of the difficulties in a study such as this is the possibility of selection bias confounding the results, but every effort was made to ensure that the patients enrolled in the study were representative of those routinely monitored in the rheumatology clinic.

The treatment of peptic ulceration in patients with RA is difficult as most require continuation of their NSAID to control the distressing symptoms of their arthritis, and yet the antirheumatic drug may be the cause of their ulcer. Several studies have explored the effect of an $\mathrm{H}_{2}$ antagonist on ulcer healing with continuation of NSAID treatment. Most studies have been uncontrolled and have shown that ulcers do heal at a rate similar to that observed in non-RA 
patients. ${ }^{78}$ One report, however, demonstrated a high ulcer healing rate on placebo, ${ }^{9}$ and another emphasised that $\mathrm{H}_{2}$ antagonists may relieve ulcer symptoms without healing and result in the risk of a silent perforation. ${ }^{10}$ Our own uncontrolled study has shown a slightly reduced ulcer healing rate in the RA group maintained on NSAIDs and treated with ranitidine, when compared with the healing rates reported for non-NSAID associated peptic ulceration. $^{11}$

Peptic ulceration in RA is often asymptomatic and this may be partly owing to the analgesic effect of the NSAIDs taken by these patients. Endoscopy is the only sure way to establish the presence of ulceration and to monitor the response to treatment.

Our own study suggests that other factors may be contributing to the high prevalence of peptic ulceration in RA, as well as NSAIDs. Smoking is important but a mucosal defect may also be contributory as atrophic gastritis is a well recognised feature of RA. ${ }^{12}$ The natural history of peptic ulceration is unknown and hence treatment remains empirical. Long term controlled studies of the effects of $\mathrm{H}_{2}$ blockers, and also of agents which enhance the integrity of the gastric mucosa, are required to determine the optimum therapeutic approach to the patient with RA and a peptic ulcer.
References

1 Caruso I, Bianchi Porro G. Gastroscopic evaluation of antiinflammatory agents. $\mathrm{Br}$ Med $J$ 1980; 280: 75-8.

2 Collier St J D, Pain J A. Non-steroidal anti-inflammatory drugs and peptic ulceration. Gut 1985; 26: 359-63.

3 CSM Update. Non-steroidal anti-inflammatory drugs and $\frac{\bar{O}}{\bar{N}}$ serious gastrointestinal adverse reactions. $\mathrm{Br}$ Med J 1986; 292: 614.

4 Somerville K, Faulkner G, Langman M. Non-steroidal antiinflammatory drugs and bleeding peptic ulcer. Lancet 1986; i: $\infty$ 462-4.

5 Willoughby J M T, Essigman W K, Weber J C P, Pinerua R F. Smoking and peptic ulcer in rheumatoid arthritis. Clin $\operatorname{Exp} \vec{\omega}$ Rheumatol 1986; 4: 31-5.

6 Taylor R T, Huskisson E C, Whitehouse G H, Dudley Hart F, Trapnell D H. Gastric ulceration occurring during indomethacin therapy. $\mathrm{Br}$ Med $J$ 1968; iv: 734-7.

7 Croker J R, Cotton P B, Boyle A C, Kinsella P. Cimetidine for peptic ulcer in patients with arthritis. Ann Rheum Dis 1980; 39: 275-8.

8 O'Laughlin J, Silvoso G R, Ivey K J. Healing of aspirin- $\infty$ associated peptic ulcer disease despite continued salicylate ingestion. Arch Intern Med 1981; 141: 781-3.

9 Davies J, Collins A J, Dixon A St J. The influence of cimetidine on peptic ulcer in patients with arthritis taking anti- $\frac{\Im}{\overparen{D}}$
inflammatory drugs. Br J Rheumatol 1986; 25: $54-8$.

10 Mitchell W S, Sturrock R D. Ulcers and anti-inflammatory agents. Br Med J 1982; 284: 731 .

11 Frost F, Rahbek I, Rune S J. Cimetidine in patients with gastric ulcer: a multicentre controlled trial. Br Med J 1978; ii: 795-7.

12 Rooney P J, Grennan D M, Sturrock R D, Brooks P M, Dick W C. Serum immunoreactive gastrin: specificity for rheumatoid arthritis, biomodality or distribution and failure of effect of anti-inflammatory drugs. Ann Rheum Dis 1976; 35: 40-5. 